\title{
Implementation of CORS GNSS and Local Geoid for Precise Orthometric Height Determination in Land Subsidence Region (A Case Study in Semarang City)
}

\author{
L M Sabri, Moehammad Awaluddin, Fauzi Janu Amarrohman \\ Departmen Teknik Geodesi - Fakultas Teknik - Universitas Diponegoro, Indonesia
}

\section{Article History:}

Received 12 November 2018

Received in revised form 10 June 2019

Accepted 11 June 2019

Available online 28 June 2019

\section{Keywords:}

Geoid, GNSS, gravity disturbance, fitting, integral of Hotine

\section{Corresponding Author:}

Laode M Sabri

Email: Imsabri@ft.undip.ac.id

\begin{abstract}
Geoid has an important role in converting geodetic heights to physical heights, both in orthometric and normal height systems. For the time being, Semarang City already has gravimetric geoid with centimeter-level precision. This gravimetric was validated by geometric geoid measured by GNSS static method. GNSS measurement using static method needs long observation time and costly because it requires network that connect baselines and points. This study aims to implement CORS GNSS in measuring geodetic height and to apply gravimetric geoid in orthometric height computations. In this research, the gravimetric geoid recomputation process was carried out using gravity disturbance data of 2016. The geoid fitting process was carried out iteratively based on gravity data and modification of the Hotine.integral. Geodetic height measurements were carried out at 40 points distributed olong $50 \mathrm{~km}$ levelling network. Geodetic height measurements were referred to CORS GNSS of BIG and UNDIP (Diponegoro University) to produce standard deviation ranged from $\pm 0.003 \mathrm{~m}$ to \pm 0.055 . Geometric geoid checking with previous gravimetric geoid before fitting produced standard deviation of $\pm 0.037 \mathrm{~m}$ and datum offset of $0.690 \mathrm{~m}$. Geometric geoid checking for recent gravimetric geoid after fitting produced standard deviation of $\pm 0.043 \mathrm{~m}$ and datum offset of $-0.010 \mathrm{~m}$. This study concluded that the referring geodetic coordinates to CORS stations by 1 hour observation of rapid static method and processing baselines in commercial software are sufficient for the determination of orthometric height in centimeterlevel precision. This study also concluded that gravimetric geoid fitting based on gravity data shifting can minimize datum offset and shrinkage in geoid map.
\end{abstract}

(C) Author(s) 2019. This is an open access article under the Creative Commons Attribution-ShareAlike 4.0 International License (CC BY-SA 4.0).

\section{Pendahuluan}

Land subsidence tidak hanya menjadi masalah bagi pembangunan fisik di Kota Semarang, tetapi juga menjadi masalah bagi pekerjaan perencanaan dan pemantauan pembangunan itu sendiri (Marfai dan King, 2007; Abidin dkk, 2010; Abidin dkk, 2012; Abidin dkk, 2015; Gumilar $\mathrm{dkk}, 2013)$. Land subsidence mengakibatkan titik-titik kontrol ketinggian di atas lapisan geologi aluvial tidak dapat digunakan sebagai acuan untuk pengukuran ketinggian. Pengukuran sipat datar yang mengacu pada Jaring Kontrol Vertikal Nasional (JKVN) orde 1 juga tidak lagi efektif dan akurat untuk pengukuran tinggi ortometrik di Kota Semarang (Sabri, 2018).
Salah satu teknik pengukuran ketinggian yang akurat dan produktif adalah pengukuran dengan Global Navigation Satellite System (GNSS ). Survei GNSS tidak memerlukan keterlihatan antar titik seperti pada survei sipat datar, sehingga pengaturan alat hanya dilakukan di atas titik. Kondisi ini secara signifikan meminimalkan kesalahan pengaturan alat, sehingga kesalahan yang masih tersisa dalam survei GNSS hanyalah kesalahan perambatan sinyal dari satelit GNSS ke receiver (Leick, 2004). Ketersediaan stasiun referensi berupa Continously Operating Reference Station (CORS) GNSS mendorong pengukuran posisi geodetik yang lebih efisien. CORS GNSS juga dapat menjadi referensi untuk mewujudkan one map policy dalam survei dan pemetaan di Indonesia (Sunantyo, 2009). 
Meskipun survei GNSS dapat menentukan posisi geodetik secara akurat, namun nilai ketinggian yang dihasilkan belum memiliki arti fisik seperti yang diinginkan pada pekerjaan engineering . Ketinggian fisik dapat dihitung melalui reduksi dengan nilai undulasi geoid dari suatu peta geoid, baik geoid geometrik maupun geoid gravimetrik (Hoffman-Wellenhof dan Moritz, 2005). Geoid geometrik umumnya diterapkan untuk proses reduksi ketinggian di wilayah yang sempit, sedangkan geoid gravimetrik lebih efektif untuk reduksi ketinggian di wilayah yang lebih luas (You, 2006).

Model geoid yang digunakan di Indonesia saat ini adalah EGM2008 (Pahlevi dkk, 2015). EGM2008 digunakan dalam Sistem Referensi Geospasial Indonesia 2013 (SRGI 2013) sebagai model geoid untuk mengkonversi tinggi geometrik yang didapat dari pengukuran GNSS menjadi tinggi ortometrik yang mengacu pada muka laut rerata. Akurasi EGM 2008 yang diaplikasikan di beberapa negara lain bervariasi. Akurasi tertinggi didapat pada pengujian di Jepang yang mencapai $\pm 0,083 \mathrm{~m}$, sementara pengujian di Amerika Serikat menghasilkan akurasi sebesar $\pm 0,248$ m (Pavlis dkk, 2008).

Presisi geoid global untuk penentuan tinggi ortometrik di Indonesia masih rendah. Pada pengujian di Kota Semarang, penentuan tinggi ortometrik berbasis GNSS dan geoid dari EGM2008, Eigen-6C4, dan GECO, secara berturut-turut adalah $\pm 0,068 \mathrm{~m}, \pm 0,066 \mathrm{~m}$, dan $\pm 0,067 \mathrm{~m}$ (Sudarsono dan Amarrohman, 2016). Tinggi ortometrik yang presisi di wilayah land subsidence diperoleh dengan prosedur pengukuran CORS GNSS yang presisi serta geoid lokal yang presisi (Sabri dkk, 2018). Saat ini geoid lokal Kota Semarang telah tersedia, namun masih memerlukan kajian lebih lanjut mengenai presisi dan kehandalan dalam implementasinya (Sabri, 2018). Atas dasar masalahmasalah tersebut, maka perlu dilakukan penelitian tentang implementasi CORS GNSS dan geoid untuk penentuan tinggi ortometrik di wilayah land subsidence dengan studi kasus Kota Semarang.

\section{Data dan Metodologi}

\subsection{Data dan Lokasi}

Daftar peralatan dan bahan yang digunakan untuk pengukuran dan pengolahan data dapat dilihat pada Tabel 2.1 dan Tabel 2.2. Data tersebut digunakan untuk menghitung geoid gravimetrik dan geoid geometrik. Geoid gravimetrik memerlukan data gangguan gayaberat yang dihitung dari data gayaberat terestris dan data ketinggian geodetik dari GNSS pada tahun 2016. Data gangguan gayaberat global dihitung dari koefisien harmonik EGM2008 dengan derajat maksimum 2190. Efek topografi di darat dan laut dihitung dari data SRTM90 dan GEBCO_2014 Grid.

Geoid geometrik memerlukan data ketinggian dari GNSS dan sipat datar. Data CORS GNSS merupakan rekaman data satelit GNSS di stasiun referensi milik Badan Informasi Geospasial (BIG) yang ada di Kota Semarang pada bulan Mei 2018. BIG menyediakan layanan data standar dengan sampling rate 30 detik. Data CORS UNDIP difasilitasi oleh PT. Adhimulia Interniagatama dengan receiver Aschtech
Promark PF800 yang beroperasi dengan samping rate 5 detik.

Tabel 2.1 Data penelitian

\begin{tabular}{lll}
\hline No. & \multicolumn{1}{c}{ Nama } & \multicolumn{1}{c}{ Spesifikasi } \\
\hline 1 & Gangguan gayaberat & Cakupan $1^{\circ} \times 1^{\circ}$ \\
2 & EGM2008 & nmak $=2190$, \\
3 & SRTM90 & Resolusi spasial 3" \\
4 & GEBCO_2014 Grid & Resolusi spasial 30" \\
5 & TTG449 & JKVN orde 1 \\
6 & CORS Semarang & Sampling rate 30 detik \\
7 & CORS UNDIP & Sampling rate 5 detik \\
\hline
\end{tabular}

Pengukuran posisi geodetik titik pengamatan gayaberat dilakukan dengan metode rapid statik yang terikat pada stasiun CORS GNSS yang dikelola oleh UNDIP dan BIG. Pengolahan baseline GNSS dilakukan dengan bantuan perangkat lunak TopCon Tools 8.5. Pengukuran tinggi ortometrik atau tinggi normal dilakukan dengan sipat datar dijital merk Geomax tipe ZDL700 untuk memenuhi spesifikasi kelas LA pada SNI JKVN.

Tabel 2.2 Peralatan penelitian

\begin{tabular}{lll}
\hline No. & \multicolumn{1}{c}{ Nama } & \multicolumn{1}{c}{ Spesifikasi } \\
\hline 1 & TopCon Hiper SR & Receiver GNSS rover \\
& & \\
2 & Geomax ZDL700 & Sipat datar \\
3 & Gravsoft 2.9.7 & Perhitungan geoid \\
4 & Simply Fortran 2 & Pemrograman \\
\hline
\end{tabular}

\subsection{Metodologi}

Implementasi metode penentuan tinggi ortometrik presisi memerlukan kajian tentang presisi hasil pengukuran GNSS yang terikat pada CORS GNSS dan presisi dari peta geoid yang sudah ada. Secara umum, penelitian ini membandingkan tinggi ortometrik dari pengukuran GNSS dan geoid terhadap tinggi ortometrik dari ukuran sipat datar di titik-titik sampel.

Pengujian akurasi metode penentuan tinggi ortometrik dengan GNSS dan geoid dilakukan pada 40 titik pengecekan independen atau Independent Check Point (ICP). Titik-titik tersebut terdistribusi pada jalur sipat datar sepanjang lebih dari $50 \mathrm{~km}$ dengan interval jarak antara titik sekitar 2 hingga $3 \mathrm{~km}$. Pengukuran sipat datar dilakukan dengan metode double stand pergi-pulang.

Presisi tinggi ortometrik berbasis GNSS pada dasarnya merupakan perambatan kesalahan dari akurasi geoid dan akurasi dari ukuran GNSS. Pengukuran yang terikat pada dua stasiun CORS secara simultan mengakibatkan terjadinya ukuran lebih dan proses perataan pada penentuan tinggi geodetik definitif. Presisi tinggi ortometrik dari sipat datar dikontribusi oleh akurasi titik referensi dan kesalahan penutup pengukuran sipat datar.

Geoid gravimetrik pada tahun 2018 dihitung dengan data gangguan gayaberat terestris yang diukur pada tahun 2016. Gangguan gayaberat diperoleh dari pengukuran gayaberat dan GNSS. Nilai gangguan gayaberat dihitung dengan persamaan (1) (Hoffman-Wellenhof dan Moritz, 2005)

$$
\delta g=g_{P}-\gamma_{P}
$$


dalam hal ini $g_{p}$ adalah gayaberat yang sebenarnya di permukaan bumi dan $\gamma_{p}$ adalah gayaberat normal di permukaan bumi.

Data gravitasi terukur dapat diklasifikasikan menjadi tiga jenis panjang gelombang, yaitu panjang gelombang pendek, sedang, dan panjang. Panjang gelombang pendek disumbangkan oleh efek topografi. Gelombang panjang disumbangkan oleh gayaberat global bumi seperti pada persamaan (2) (Hoffman-Wellenhof dan Moritz, 2005).

$$
\zeta_{M G G}=R \cdot \sum_{n=2}^{N} \sum_{m=0}^{l} \bar{P}_{n m} \cdot(\sin \varphi) \cdot\left(\Delta \bar{C}_{l m} \cdot \cos m \lambda+\Delta \bar{S}_{l m} \cdot \sin m \lambda\right)
$$

dalam hal ini R adalah jari-jari bumi, $\bar{P}_{n m}$ adalah fungsi Legendre, $\Delta \bar{C}_{l m}$ dan $\Delta \bar{S}_{l m}$ adalah koefisien untuk komponen cosinus dan sinus. Panjang gelombang medium adalah data gravitasi yang disumbangkan oleh kontras densitas di bawah permukaan bumi. Interpolasi nilai distorsi gravitasi terestrislangsung dengan integral Hotine dapat menurunkan ketepatan penentuan geoid. Efek global harus dihilangkan dari data gayaberat Proses menghilangkan efek pada gangguan gravitasi dan mengembalikannya dalam bentuk undulasi geoid dikenal sebagai teknik Remove-Compute-Restore R-C-R. Penerapan teknik R-C-R bertujuan untuk memperoleh nilai gangguan gayaberat yang tidak dipengaruhi oleh efek global dan topografi.

Langkah pertama R-C-R adalah perhitungan gangguan gayaberat residu menggunakan persamaan (3) (HoffmanWellenhof dan Moritz, 2005).

$$
\delta g_{R E S}=\delta g_{P}-\delta g_{E G M 2008}
$$

dalam hal ini $\delta g_{R E S}$ adalah gangguan gayaberat di permukaan, $\delta g_{E G M 2008}$ adalah gangguan gayaberat dari EGM2008.

Gangguan gravitasi residu kemudian diinterpolasi dengan metode Krigging dalam ukuran grid tertentu untuk memperoleh gangguan gayaberat grid $\left(\delta g_{G R I D}\right)$. Paramater krigging seperti varian nol dan ukuran grid sangat berpengaruh terhadap presisi geoid. Pada penelitian ini, varian nol dan ukuran grid adalah 0,300 mgal dan $0,01^{\circ}$ Perhitungan krigging menggunakan fungsi Gauss-Markov orde satu, seperti pada persamaan (4) (Doganalp, 2015).

$$
C(q)=C_{0} \cdot\left(1+\frac{q}{q_{0}}\right) \cdot e^{-\frac{q}{q_{0}}}
$$

dalam hal ini notasi $C_{0}$ adalah varian, $q_{0}$ adalah koefisien jarak, dan $q$ adalah jarak antar titik. Nilai gangguan gayaberat dihitung dengan prinsip rerata berbobot dengan nilai varian sebagai bobot, seperti pada persamaan (5) (Wolf dan Ghillani, 2005).

$$
\delta g_{\text {GRID }}=\delta g\left(\varphi^{\prime}, \lambda^{\prime}\right)=\frac{\delta g_{1} \cdot \frac{1}{C_{1}}+\delta g_{2} \cdot \frac{1}{C_{2}}+\cdots+\delta g_{n} \cdot \frac{1}{C_{n}}}{\frac{1}{C_{1}}+\frac{1}{C_{2}}+\cdots+\frac{1}{C_{n}}}
$$

Jarak sferis $(\psi)$ antara titik evaluasi $(\varphi, \lambda)$ dan titik grid $\left(\varphi^{\prime}, \lambda^{\prime}\right)$ dihitung dengan persamaan (6) (HoffmanWellenhof dan Moritz, 2005).

$$
\cos \psi=\sin \varphi \cdot \sin \varphi^{\prime}+\cos \varphi \cdot \cos \varphi^{\prime} \cdot \cos \left(\lambda^{\prime}-\lambda\right)
$$

Jarak sferis tersebut kemudian digunakan untuk menghitung fungsi Hotine pada persamaan (7) (HoffmanWellenhof dan Moritz, 2005).

$$
H(\psi)=\frac{1}{\sin \frac{\psi}{2}}-\ln \left(1+\frac{1}{\sin \frac{\psi}{2}}\right)
$$

Undulasi geoid residu dihitung dengan persamaan (8) (Hoffman-Wellenhof dan Moritz, 2005).

$$
\zeta_{R E S}(\varphi, \lambda)=\frac{R}{4 \cdot \pi \cdot \gamma} \iint_{\sigma} \delta g\left(\varphi^{\prime}, \lambda^{\prime}\right)+G_{1}\left(\varphi^{\prime}, \lambda^{\prime}\right) \cdot H(\psi) \cdot d \sigma
$$

dalam hal ini d $\sigma$ adalah luas grid dan $G_{1}$ adalah adalah koreksi medan. Koreksi medan dihitung dengan persamaan (9).

$$
G_{1}(\theta, \lambda)=\frac{R^{2}}{2 \pi} \iint_{\sigma} \frac{H^{n}\left(\varphi^{\prime}, \lambda^{\prime}\right)-H^{n}(\varphi, \lambda)}{l_{0}^{3}} \cdot \delta g\left(\varphi^{\prime}, \lambda^{\prime}\right) \cdot d \sigma
$$

Undulasi geoid gravimetrik diperoleh dengan pengembalian (Restore) efek Global Geopotential Model pada geoid residuditunjukkan oleh persamaan (10) (Sneeuw, 2006).

$$
\zeta_{G R A}(\varphi, \lambda)=\zeta_{R E S}(\varphi, \lambda)+\zeta_{E G N 2008}(\varphi, \lambda)
$$

Presisi model geoid gravimetrik diuji dengan menghitung selisih terhadap geoid geometrik $\left(\zeta_{G E O}(\varphi, \lambda)\right)$ dari ukuran sipat datar dan GNSS seperti pada persamaan (11).

$$
\partial \zeta(\varphi, \lambda)=\zeta_{G R A}(\varphi, \lambda)-\zeta_{G E O}(\varphi, \lambda)
$$

Rerata simpangan dihitung dengan persamaan (12).

$$
\partial \bar{\zeta}=\frac{\sum_{i}^{n} \partial \zeta_{i}}{n}
$$

Pada penelitian ini, besarnya rerata simpangan geoid mengindikasikan nilai offset datum vertikal. Presisi geoid gravimetrik didefinisikan sebagai nilai simpangan baku yang dihitung dengan persamaan (13) (Wolf dan Ghillani, 2000).

$$
S=\sqrt{\frac{\sum\left(\partial \zeta_{i}-\partial \bar{\zeta}\right)^{2}}{n}}
$$

Offset datum vertikal yang mendekati nilai nol mengindikasikan bahwa pengukuran gayaberat, GNSS, dan sipat datar menggunakan referensi yang sama. Pada kasus terjadinya offset datum yang signifikan, geoid gravimetrik harus melalui tahapan fitting. Pada penelitian ini, proses fitting dilakukan dengan metode fitting gravimetrik. Besarnya nilai yang ditambahkan pada data gangguan gayaberat dapat dihitung dengan memodifikasi persamaan umum pada persamaan (8) menjadi persamaan (14)

$$
\partial \delta g=\partial \bar{\zeta} \cdot \frac{4 \cdot \pi \cdot \gamma}{R \cdot H(\psi) \cdot d \varphi^{\prime} \cdot d \lambda^{\prime}}
$$

Pada penelitian ini, nilai $R$ dan $\gamma$ adalah jari-jari rerata Gauss dan gayaberat normal di titik pangkal gayaberat di Kota Semarang masing-masing sebesar 6357393,130 m dan 978110,280 mgal. Dengan asumsi bahwa jarak sferis $1^{\circ}$ dan ukuran grid $1^{\circ}$, maka diperoleh rumus empirik 
untuk menghitung offset gangguan gayaberat pada persamaan (15).

$$
\partial \delta g=58,21582197 . \partial \bar{\zeta}
$$

\section{Hasil dan Pembahasan}

Perhitungan geoid gravimetrik pada penelitian ini menggunakan data gangguan gayaberat di permukaan bumi. Data gangguan gayaberat tahun 2018 berkisar antara -32,329 mgal hingga 176,796 mgal. Reduksi data terestris dengan EGM2008 n=2190 menghasilkan gangguan gayaberat residu yang berkisar antara $-42,899$ mgal hingga 19,141 mgal. Gridding dengan metode Krigging menghasilkan peta dengan rentang

42,73 mgal hingga 21,92 mgal, seperti tampak pada Gambar 3.1. Di wilayah Kota Semarang, gangguan gayaberat residu sebelum proses fitting gravimetrik berkisar antara -15 mgal hingga 10 mgal.

Perhitungan integral Hotine berbasis data gangguan gayaberat residu sebelum fitting gravimetrik menghasilkan geoid gravimetrik Kota Semarang yang berkisar antara 25,65 m hingga 26,32 m, seperti tampak pada Gambar 3.2. Geoid gravimetrik tersebut selanjutnya diuji pada 40 titik geoid geometrik. Ketinggian ortometrik titik-titik utama untuk validasi telah diukur dengan metode sipat datar pada tahun 2016, sedangkan pengukuran tahun 2018 bertujuan untuk perapatan titik.

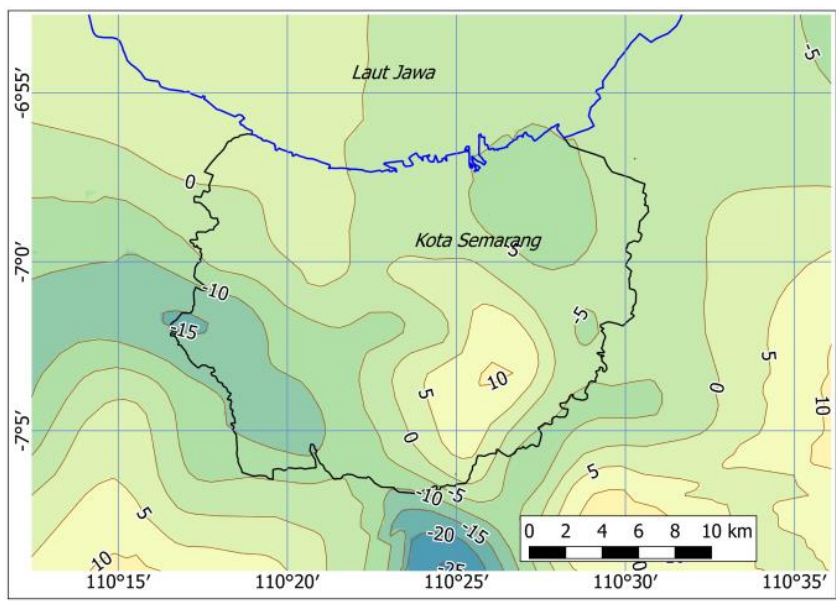

Gambar 3.1 Peta gangguan gayaberat residu sebelum fitting

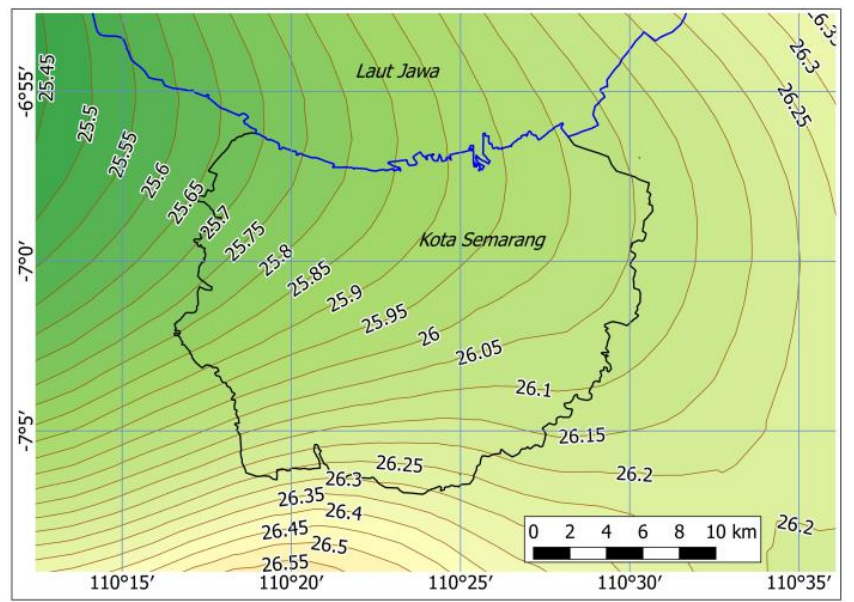

Gambar 3.2 Peta geoid sebelum fitting
Ketinggian geodetik titik-titik geoid geometrik diukur dengan metode statik singkat selama 1 jam. Setiap titik pengukuran diikatkan pada CORS CSEM dan CORS UNDIP yang beroperasi selama 24 jam. Hasil reduksi baseline yang terikat CSEM dan CDIP dapat dilihat pada Tabel 3.1 dan Tabel 3.2. Berdasarkan tabel-tabel tersebut terlihat bahwa penggunaan data dengan sampling rate 5 detik dan 30 detik tidak berdampak signifikan terhadap presisi baseline. Pada tabel tersebut terlihat bahwa baseline dengan panjang lebih dari $9 \mathrm{~km}$ diolah dengan teknik bebas ionosfer, sehingga berpotensi menurunkan presisi dari penentuan tinggi ortometrik berbasis pengamatan GNSS dan geoid.

Tabel 3.1 Reduksi baseline terikat stasiun CORS CSEM

\begin{tabular}{|c|c|c|c|}
\hline $\begin{array}{c}\text { Jenis Solusi } \\
\text { Ambiguitas } \\
\text { Fase }\end{array}$ & $\begin{array}{c}\text { Rentang } \\
\text { Panjang } \\
\text { Baseline } \\
\text { (km) }\end{array}$ & $\begin{array}{c}\text { Rentang } \\
\text { Simpangan } \\
\text { Baku Tinggi } \\
\text { Geodetik (m) }\end{array}$ & $\underset{\mathbf{h}}{\mathbf{J u m l a}}$ \\
\hline Integer & 0,249 s.d. 9,303 & $\begin{array}{l}0,003 \text { s.d. } \\
0.035\end{array}$ & 28 \\
\hline $\begin{array}{l}\text { Integer dan } \\
\text { bebas } \\
\text { ionosfer }\end{array}$ & 12,291 s.d. 13,19 & $\begin{array}{l}0,018 \text { s.d. } \\
0,046\end{array}$ & 12 \\
\hline
\end{tabular}

Tabel 3.2 Reduksi baseline terikat stasiun CORS UNDIP

\begin{tabular}{|c|c|c|c|}
\hline $\begin{array}{c}\text { Jenis Solusi } \\
\text { Ambiguitas } \\
\text { Fase }\end{array}$ & $\begin{array}{c}\text { Rentang } \\
\text { Panjang } \\
\text { Baseline } \\
\text { (km) }\end{array}$ & $\begin{array}{c}\text { Rentang } \\
\text { Simpangan } \\
\text { Baku Tinggi } \\
\text { Geodetik (m) }\end{array}$ & $\underset{\mathbf{h}}{\text { Jumla }}$ \\
\hline Integer & 3,277 s.d. 9,200 & $\begin{array}{l}0,010 \text { s.d. } \\
0.022\end{array}$ & 29 \\
\hline $\begin{array}{l}\text { Integer dan } \\
\text { bebas } \\
\text { ionosfer }\end{array}$ & 9,620 s.d. 13,154 & $\begin{array}{l}0,024 \text { s.d. } \\
0,055\end{array}$ & 11 \\
\hline
\end{tabular}

Hasil uji geoid gravimetrik dapat dilihat pada Tabel 3.3. Simpangan baku geoid sebelum proses fitting adalah \pm 0,037 m. Sedangkan rerata simpangan antara geoid gravimetrik dan geoid geometrik adalah $-0,690 \mathrm{~m}$. Jika menerapkan rumus empirik fitting gayaberat pada persamaan (14), maka faktor fitting yang harus ditambahkan pada data gangguan gayaberat residu sebesar -39,703 mgal.

Tabel 3.3 Validasi geoid gravimetrik sebelum fitting

\begin{tabular}{cc}
\hline Simpangan & Geoid Sebelum Fitting $(\mathbf{m})$ \\
\hline Minimum & $-0,776$ \\
Maksimum & $-0,612$ \\
Rentang & 0,164 \\
Rerata & $-0,690$ \\
Simpangan baku & $\pm 0,037$ \\
\hline
\end{tabular}

Nilai offset datum diminimalkan dengan proses fitting secara empirik. Gangguan gayaberat sesudah fitting berkisar antara -3,281 mgal hingga 58,758 mgal. Gridding 
dengan metode krigging menghasilkan peta gangguan gayaberat residu dengan rentang $\quad-2,935$ mgal hingga 59,753 mgal, seperti pada Gambar 3.3. Perhitungan integral Hotine menghasilkan geoid gravimetrik hasil fitting dengan rentang 26,22 $\mathrm{m}$ hingga 27,02 $\mathrm{m}$, seperti pada Gambar 3.4.

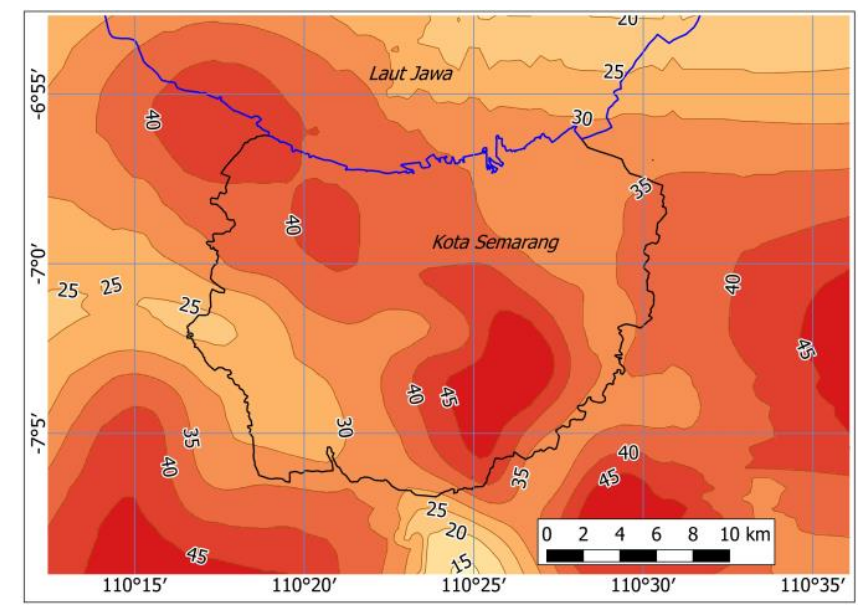

Gambar 3.3 Peta gangguan gayaberat residu fitting di Kota Semarang

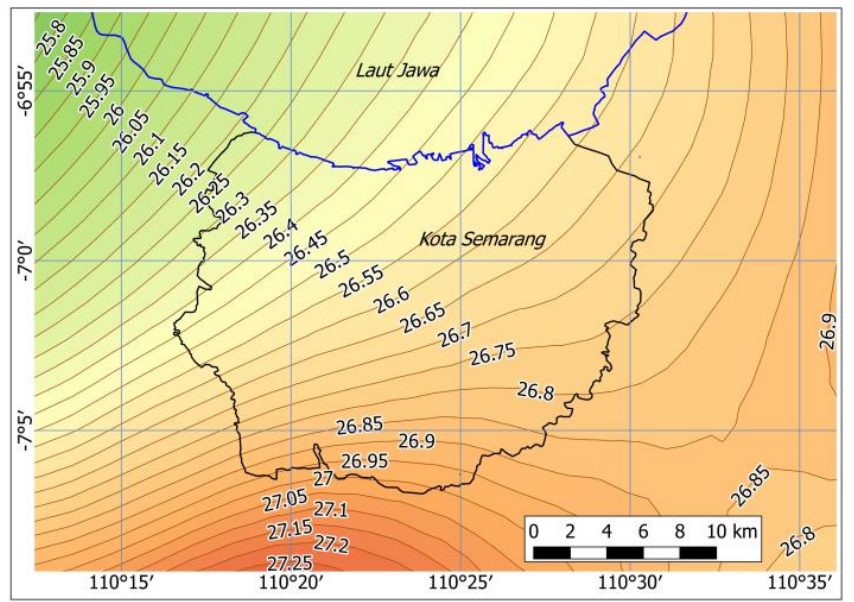

Gambar 3.4 Peta gangguan gayaberat residu fitting di Kota Semarang

Hasil validasi geoid gravimetrik hasil fitting terhadap geoid geometrik dapat dilihat pada Tabel 3.4. Simpangan baku geoid hasil fitting lebih besar daripada sebelum fitting yaitu $\pm 0,043 \mathrm{~m}$. Hal ini diduga dikontribusi oleh kesalahan pada perhitungan peraatan kolokasi kuadrat terkecil pada proses gridding. Secara teoritis, semakin besar nilai yang diinterpolasi, maka semakin besar kemungkinan kesalahan interpolasi yang terjadi.

\begin{tabular}{cc} 
Tabel 3.4 Validasi geoid gravimetrik sesudah fitting \\
\hline Simpangan & Geoid Sesudah Fitting $\mathbf{( m )}$ \\
\hline Minimum & $-0,087$ \\
Maksimum & 0,066 \\
Rentang & 0,153 \\
Rerata & $-0,010$ \\
Simpangan baku & $\pm 0,043$
\end{tabular}

Tabel 3.4 terlihat bahwa nilai rerata simpangan geoid gravimetrik setelah fitting adalah $-0,010 \mathrm{~m}$. Hal ini mengindikasikan bahwa proses fitting telah berhasil memperkecil nilai offset antara referensi pengukuran. Berdasarkan uji statikstik dengan selang kepercayaan 95\%, nilai offset tidak berbeda secara signifikan terhadapnilai simpangan baku geoid. Fakta tersebut mengindikasikan bahwa proses iterasi tidak perlu dilakukan.

\section{Kesimpulan}

Hasil pengukuran GNSS metode statik singkat selama 1 jam pengamatan yang terikat pada stasiun CORS dalam jarak kurang dari $10 \mathrm{~km}$ dapat menghasilkan tinggi geodetik yang presisi untuk perhitungan tinggi ortometrik. Panjang baseline yang berkisar antara $10 \mathrm{~km}$ hingga 20 $\mathrm{km}$ disarankan diukur dengan pengamatan selama 2 jam untuk mendapatkan ambiguitas fase yang integer.

Proses fitting data gangguan gayaberat secara empirik berhasil memperkecil nilai offset datum yang digunakan sebagai referensi pengukuran gayaberat, sipat datar, dan GNSS. Fitting data gangguan gayaberat secara empirik menghasilkan peta geoid fitting dengan bentuk yang hampir sama dengan bentuk geoid gravimetrik sebelum fitting.

\section{Pernyataan Konflik Kepentingan}

Penulis menyatakan tidak ada konflik kepentingan dalam artikel ini (The authors declare no competing interest).

\section{Referensi}

Abidin, H. Z., Andreas, H., Gumilar, I., Sidiq, T. P., Gamal, M., Murdohardono, D., Supriyadi, S., dan Fukuda, Y. (2010). Studying Land Subsidence in Semarang (Indonesia) Using Geodetic Methods. FIG Congress 2010 Facing the Challenges - Building the Capacity, 11-16 April 2010., Sydney, Australia.

Abidin, H. Z., Andreas, H., Gumilar, I., Sidiq, T. P., dan Fukuda, Y. (2012). Land Subsidence in coastal city of Semarang (Indonesia), Geomatics, Natural hazards and Risk, 2012, DOI:10.1080/19475705.2012.692336.

Abidin, H. Z., Andreas, H., Gumilar, I., Sidiq, T.P., dan Gamal, M. (2015). Environmental Impact of Land Subsidence in Urban Areas of Indonesia, FIG Working Week 2015, From the wisdom of the ages to the challenges of modern world, 17-21 May 2015. Sofia, Bulgaria.

Amos, M. J., dan Featherstone, W. E. (2003). A Comparison of Gridding Techniques for Terrestrial Gravity Observations in New Zealand. New Zealand Surveyor.

Doganalp, S. (2016). Geoid Height Computation in StripArea Project by Using Least Squares Collocation. Acta Geodyn. Geomater., Vol. 13, No. 2 (182), Hal. 167-176.

Gumilar, I., Abidin, H. Z., Sidiq, T. P., Andreas, H., Maiyudi, R., Gamal, M., dan Fukuda, Y. (2013). Mapping and Evaluating The Impact of Land Subsidence in 
Semarang (Indonesia), Indonesian Journal of Geospatial, Vol. 2, 2013, Hal. 26-41.

Hofmann-Wellenhof, B., dan Moritz, H. (2005). Physical Geodesy. Springer, Berlin.

Kasenda, A. (2009). Height Precision of Geoid for Modernization of Geoid of Indonesia. Disertasi. University of New South Wales, Australia

Leick, A.(2004). GPS Satellite Surveying. John Wiley \& Sons.

Li, F., Yue, J., dan Zhang, L. (2005). Determination of Geoid by GPS/Gravity. Chinese Journal of Geophysics, Vol. 48, Hal. 326-330.

Marfai, M.A., dan L. King, L. (2007). Monitoring Land Subsidence in Semarang, Indonesia. Environmental Geology, 53, Hal. 651-659.

Pahlevi, A., Pangastuti, D., Sofia, N., Kasenda, A., dan Prijatna, K. (2015). Determination of Gravimetric Geoid Model in Sulawesi - Indonesia. FIG Working Week 2015, 17-21 May 2015, Sofia, Bulgaria.

Pavlis, N.K., Holmes, S.A., Kenyon, S.C., dan Factor, J.K. (2008). The Development and Evaluation of The Earth Gravitational Model 2008 (EGM2008). National Geospatial-Intelegence Agency, Missouri, Amerika Serikat.

Sabri, L. M. (2018). Sistem referensi vertikal di wilayah land subsidence (studi kasus: Kota Semarang). Disertasi, Universitas Gadjah Mada, Yogyakarta.
Sabri, L. M., Heliani, L. S., Sunantyo, T. A., dan Widjajanti, N. (2018). Combination of gravity disturbances and gravity anomalies for geoid determination: a case study in Semarang city, Central Java, Indonesia. The $4^{\text {th }}$ International Conference on Science and Technology, 7 - 8 Agustus 2018, Yogyakarta.

Sanso, F. dan M. Sideris, 2013. Geoid Determination: Theory and Methods. Springer.

Sneeuw, N. (2006). Physical Geodesy. Stutgart University, Stutgart, Jerman.

Sudarsono, B. dan Ammarohman, F. J. (2016). Uji akurasi model geoid global untuk penentuan tinggi ortometrik di wilayah land subsidence. Prosiding CGISE 2016. Yogyakarta.

Sunantyo, T.A. (2009) GNSS CORS Infrastructure and Standard in Indonesia. $7^{\text {th }}$ FIG Regional Conference. Hanoi, Vietnam

Triarahmadhana, B. dan Heliani, L. S. (2014). Evaluation of GOCE's Global Geopotential Model to The Accuracy of Local Geoid (Case Study: Java Island, Indonesia), FIG Congress 2014, Kuala Lumpur, Malaysia.

Wolf, P. R., \& Ghillani, C. D. (2006). Adjustment Computations: Spatial Data Analysis. John Wiley \& Sons, Inc.

You, R-J. (2006). Local Geoid Improvement using GPS and Leveling Data. Journal of Surveiing Engineering, Vol. 132, Hal. 101-107. 